\title{
Las empresas multiservicios en el sector público: novedades incorporadas desde la Ley 9/2017
}

\author{
Multiservice companies in the public sector: news incorporated \\ since Law 9/2017
}

\author{
Susana Rodríguez Escanciano \\ Universidad de León (España) \\ ORCID: https://orcid.org/0000-0001-5910-2982 \\ srode@unileon.es
}

\begin{abstract}
NOTA BIOGRÁFICA
Licenciada y Doctora en Derecho por la Universidad de León. Profesora Titular de Universidad (excedente) y en la actualidad, desde el año 2011, Catedrática de Derecho del Trabajo y de la Seguridad Social de la Universidad de León. Cuatro sexenios de investigación. Autora de numerosas monografías, artículos doctrinales y capítulos de libro sobre temas relacionados con la materia de su especialidad. Miembro del consejo asesor de varias revistas jurídicas. Investigadora en más de cincuenta proyectos de investigación financiados por instituciones públicas o privadas. Ha impartido más de cien conferencias en distintos foros nacionales e internacionales. Ha sido galardonada con numerosos premios de investigación nacionales por sus estudios jurídicos. Entre otros: Primer Premio del Centro de Estudios Financieros, año 1995, año 2006 y año 2008; Primer Premio Nacional «Protección de datos personales», concedido por la Agencia Nacional de Protección de Datos (1997); Premio «Rafael Martínez Emperador», del Consejo General del Poder Judicial (1997); Primer premio de Artículos Jurídicos «García Goyena» (2003); Premio de investigación sobre energías renovables, obra social de Caja España (2004); Premio de estudio e investigación sobre las Administraciones Públicas Canarias del Instituto Canario de Administración Pública (2006); Premio Adolfo Posada, del Instituto Asturiano de Administración Pública (2007); Premio de artículos jurídicos en versión castellana «Degá Miquel Frontera», otorgado por el llustre Colegio de Abogados de Islas Baleares (2007); Premio de investigación sobre violencia de género, concedido por la Fundación Balear contra la Violencia de Género y la Cátedra de Estudios de Violencia de Género (2007); Premio Ciencias de la Salud. Fundación Caja Rural de Granada (Modalidad Investigación) (2008); Premio Blas Infante del Instituto Andaluz de Administración Pública (2008); Premio de investigación Consejo Económico y Social de Castilla y León (2010); Premio Revista Jurídica La Ley (2012); Premio Fernando Albi, Diputación de Alicante (2012); Premio 8 de marzo. Igualdad de las Mujeres, otorgado por la Asociación Española de Derecho del Trabajo y de la Seguridad Social (2018).
\end{abstract}

\section{RESUMEN}

Cierto es que la utilización de técnicas de descentralización productiva no se limita al sector privado, sino que también ha penetrado y cuenta ya con general y fuerte implantación en el sector público, en el que llega a estar presente en casi todas sus actividades, tanto en las precisas para el funcionamiento ordinario de las entidades que lo componen (vigilancia, limpieza de locales, mantenimiento de instalaciones y equipos, gestión administrativa, etc.), como en las necesarias para dispensar servicios de interés general a los ciudadanos. No menos verdad resulta que esta gestión indirecta ha conllevado una acusada devaluación

1 Artículo publicado en el marco del proyecto de investigación financiado por el INAP: "Público y privado en la gestión de los servicios públicos: reestructuración, externalización y reversión a la Administración". 
de las condiciones laborales de los trabajadores al servicio de las empresas contratistas o concesionarias ante la generalización de procesos de licitación low prize, participados por empresas multiservicios, las cuales, aprovechando la ausencia de una normativa ad hoc, se caracterizan por la reducción de los costes salariales y otros estándares laborales. Ante esta realidad, no puede sino valorarse de forma positiva la apuesta que desde la Ley 9/2017, de Contratos del Sector Público, se ha realizado en aras a garantizar el cumplimiento de los convenios colectivos sectoriales, siendo necesario, no obstante, que el legislador laboral proporcione cumplida respuesta a las lagunas todavía existentes, sobre todo en los supuestos de subcontratación, donde las responsabilidades empresariales quedan ampliamente diluidas.

\title{
PALABRAS CLAVE
}

Gestión indirecta de servicios públicos; Administraciones Públicas; descentralización; responsabilidades laborales; precariedad en el empleo.

\begin{abstract}
It is true that the use of productive decentralization techniques is not limited to the private sector, but has also penetrated and already has a general and strong presence in the public sector, in which it is present in almost all its activities, both in those required for the ordinary functioning of the entities that comprise it (surveillance, cleaning of premises, maintenance of facilities and equipment, administrative management, etc.), as well as those necessary to provide services of general interest to citizens. No less true is that this indirect management has led to a hard devaluation of the working conditions of workers at the service of contractor companies or concessionaires before the generalization of low-price bidding processes, participated by multi-service companies, which, taking advantage of the absence of an own regulation, are characterized by the reduction of wage costs and other labor standards. Faced with this reality, we can only value positively the bet that since the Law 9/2017, of Public Sector Contracts, has been made in order to guarantee the fulfillment of sectoral collective agreements, being necessary, nevertheless, that the Labor legislator provides a full response to the gaps still existing, especially in the cases of subcontracting, where business responsibilities are largely diluted.
\end{abstract}

\section{KEYWORDS}

Indirect management of public services; public administrations; decentralization; labor responsibilities; precarious employment.

\author{
SUMARIO \\ 1. LA APUESTA POR LA GESTIÓN INDIRECTA DE LOS SERVICIOS PÚBLICOS. ASPECTOS POSI- \\ TIVOS Y SU LADO OSCURO: EL AHORRO DE COSTES DERIVADO DE LICITACIONES LOW PRI- \\ ZE. 2. EL EJERCICIO DE PRERROGATIVAS PÚBLICAS COMO VETO A LA DESCENTRALIZACIÓN: \\ UN CONCEPTO DE AMPLIOS CONTORNOS. 2.1. LOS ESCASOS LÍMITES AL RECLUTAMIENTO \\ TEMPORAL INDIRECTO. 2.2. LA «PAUPERIZACIÓN» DE LAS CONDICIONES DE TRABAJO DE LOS \\ ASALARIADOS AL SERVICIO DE CONTRATISTAS Y CONCESIONARIOS. 2.3. LA INESTABILIDAD \\ LABORAL INHERENTE. 2.4. INCREMENTO DE LA CONFLICTIVIDAD COLECTIVA. 3. LAS MEDIDAS \\ CORRECTORAS INTRODUCIDAS POR LA LEY 9/2017. LA APUESTA POR EL PROGRESO EN LAS \\ CONDICIONES DE TRABAJO. 3.1. LA TRANSVERSALIDAD DE LAS CLÁUSULAS SOCIALES COMO \\ INSTRUMENTOS TUITIVOS DE LOS DERECHOS DE LOS TRABAJADORES. 3.2. LA EXCLUSIÓN DE \\ OFERTAS ANORMALMENTE BAJAS: EL CUMPLIMIENTO DE LOS CONVENIOS SECTORIALES EN \\ CUANTO A CONDICIONES SALARIALES SE REFIERE. 3.3. PRESUPUESTO BASE DE LA LICITA- \\ CIÓN. 3.4. CONDICIONES ESPECIALES DE EJECUCIÓN. 3.5. POSIBLE RESOLUCIÓN DEL CONTRA- \\ TO ADMINISTRATIVO POR IMPAGOS SALARIALES. 4. EL OLVIDO DE LOS PELIGROS LABORALES \\ DERIVADOS DEL ENCADENAMIENTO DE CONTRATOS. 4.1. LA ADMISIBILIDAD DE LA SUBCON- \\ TRATACIÓN COMO POSTULADO DE LA LEGISLACIÓN ADMINISTRATIVA. 4.2. LA IMPUTABILIDAD \\ GLOBAL FRENTE A LA ADMINISTRACIÓN DEL ADJUDICATARIO INICIAL A LA LUZ DE LA LEY DE \\ CONTRATOS DEL SECTOR PÚBLICO. 4.3. LAS RESPONSABILIDADES DESDE EL PUNTO DE VISTA \\ DEL IUS LABORUM. 4.4. EL LIMITADO JUEGO DEL PRINCIPIO DE SOLIDARIDAD EMPRESARIAL. \\ 4.5. EL CONCEPTO «PROPIA ACTIVIDAD» COMO REQUISITO SINE QUA NON PARA GENERAR LA \\ CORRESPONSABILIDAD. 4.6. LA INOPERANTE REGLA DE LA SUBSIDIARIEDAD. 4.7. SITUACIONES \\ DE DESPROTECCIÓN. 5. CONCLUSIÓN. 6. REFERENCIAS BIBLIOGRÁFICAS.
}




\section{LA APUESTA POR LA GESTIÓN INDIRECTA DE LOS SERVICIOS PÚBLICOS. ASPECTOS POSITIVOS Y SU LADO OSCURO: EL AHORRO DE COSTES DERIVADO DE LICITACIONES LOW PRIZE}

Las presiones para el ahorro de costes de personal, como importante contribución en aras a la reducción del déficit público, ha tenido como efectos más destacados no sólo el recurso a aquellas modalidades de contratación laboral más económicas (singularmente temporales) y que menor compromiso de gasto implican, sino también la opción frecuente por la prestación indirecta de servicios a los ciudadanos por medio de agentes privados, quienes, tras un procedimiento reglado en competencia, asumen la realización de parcelas asociadas a las atribuciones de las Administraciones. Este devenir ha alcanzado en las últimas décadas un acusado desarrollo.

En efecto, la tipicidad de las técnicas de descentralización productiva no se limita al sector privado, sino que también ha penetrado y cuenta ya con general y fuerte implantación en el sector público, en el que llega a estar presente en casi todas sus actividades, tanto en las precisas para el funcionamiento ordinario de las entidades que lo componen (vigilancia, limpieza de locales, mantenimiento de instalaciones y equipos, gestión administrativa, etc.), como en las precisas para dispensar a los ciudadanos las prestaciones o servicios inherentes al Estado de Bienestar (Garate, 2018: 32).

En el entorno mercantil, la atribución a sujetos ajenos de una porción de la producción es una práctica harto común, que además se considera como un factor de eficiencia y eficacia desde el punto de vista del beneficio industrial. Bajo la premisa cierta de que las corporaciones pueden tener dificultades para realizar de forma competitiva todos y cada uno de los cometidos que componen su quehacer productivo, que pueden ser muy disímiles teniendo en cuenta la interactuación en mercados globalizados, se tiende hacia la especialización, concentrándose en el núcleo duro y central de su actividad (core business), prefiriendo encomendar a otros empresarios externos la realización de tareas auxiliares o anexas.

Bajo estas mismas premisas, la hipótesis de que la Administración encomiende a agentes extramuros de su estructura interna determinadas tareas puede resultar un destacado acicate, en una primera aproximación, a la hora de proporcionar servicios públicos a los ciudadanos por varias razones fundamentales:

En primer lugar, la concertación con empresas contratistas o concesionarias, adjudicatarios de un contrato, que aportan sus elementos materiales y humanos e infraestructuras a la prestación del cometido público asumido va a permitir una directa aplicación del postulado de la competencia o del incremento de la rentabilidad también en el seno de los poderes adjudicadores, en la medida en que supone sustituir parcialmente parte de su mano de obra y de su organización por su consecución en el mercado, contribuyendo, a la postre, a la dinamización de la economía (Bassols, 2007: 244).

En segundo término, conlleva un acusado ahorro de costes, tan importante para reducir el endeudamiento de las arcas públicas y aligerar la presión presupuestaria, garantizando, al tiempo, la dispensa de quehaceres públicos de primera necesidad como puede ser la educación, los servicios sociales o la sanidad (Villar, 2007: 155).

En tercer lugar, este discurrir permite atender situaciones de acumulación de tareas o necesitadas de solución inmediata, a la carencia de especialización o de capacitación de los empleados públicos en algunos asuntos novedosos o a la falta de flexibilidad de algunas de las categorías del derecho administrativo funcionarial, tal y como en ocasiones ha ocurrido con los calendarios, los permisos, las licencias, las vacaciones, la jornada y los horarios de trabajo.

En cuarto lugar, estas ventajas verán multiplicados sus efectos beneficiosos si la terciarización no se queda en un primer nivel (Administración-empresario adjudicatario de la prestación del servicio), sino que se extiende sucesivamente dando lugar a una larga cadena de empresas involucradas, de suerte que el contratista o concesionario inicial cede parte de su actividad a otra u otras empresas y estas, a su vez, a otras posteriores. Esta hipótesis provoca un acusado afinamiento del organigrama burocrático acompañado de un importante beneficio económico.

Ahora bien -y como efecto negativo-, a la consecución de este objetivo ha contribuido, sin duda, la adjudicación de los contratos administrativos a empresarios que han realizado ofertas low price a la hora de dispensar servicios públicos basadas en unas condiciones de trabajo progresivamente devaluadas a lo largo de la cadena de subcontratación.

Es más, la utilización de la descentralización productiva en el sector administrativo y en el sector mercantil no son equiparables, de suerte que el primero se rige por principios tales como, entre otros, la transparencia, la publicidad, la igualdad de trato entre licitadores y no discriminación entre interesados o la tutela de 
la libre competencia empresarial, contando con una regulación propia o especial, cuyos preceptos, aunque no son incompatibles con lo dispuesto con la normativa laboral, se deben cohonestar oportunamente, no siempre de forma fácil, con dicha normativa que encuentra su esencia en la garantía de los derechos de los asalariados. Además de tales dificultades, que van a perjudicar, a la postre, a la parte más débil, es decir, a los empleados involucrados en los fenómenos de externalización, se une un dato insoslayable: la ausencia de una normatividad ad hoc permite a las empresas prestadoras de servicios esquivar la aplicación de los convenios sectoriales, eligiendo el que corresponde con aquella de las múltiples actividades que reconozca las menores retribuciones o elaborando convenios propios a escaso coste, ahorro que va a permitir participar en los procesos de licitación realizando ofertas a la baja (Merino, 2018; 134).

\section{EL EJERCICIO DE PRERROGATIVAS PÚBLICAS COMO VETO A LA DESCENTALIZACIÓN: UN CONCEPTO DE AMPLIOS CONTORNOS}

La proyección de este modelo mercantil al ámbito del sector público plantea una duda primera y principal: ¿debería existir algún tipo del límite a la decisión administrativa de externalizar? O, formulando el interrogante en otros términos, ¿qué tipo de funciones se pueden descentralizar?

La respuesta se torna sencilla: ningún problema debe de existir para que sujetos privados colaboren en el desarrollo de un quehacer público de contenido prestacional o en la dispensa de un concreto servicio, quedando preterido únicamente el ejercicio de prerrogativas que impliquen autoridad y uso de potestades públicas, esto es, tareas reservadas al «Estado» como parte de su «núcleo irreductible, irrenunciable e indisponible». Este concepto ha sido perfilado por el Tribunal de Justicia de la Unión Europea, incluyendo «aquellos poderes que son la encarnación de la soberanía del Estado y, como tales, confieren a quienes los conciertan la facultad de ejercitar prerrogativas que sobrepasan el ámbito del Derecho común, implicando privilegios y poderes coercitivos que obligan a los ciudadanos ${ }^{2}$. Es decir, quedaría vetada la descentralización de aquel tipo de cometidos «que tengan una directa trascendencia para la situación jurídica de los ciudadanos y que, por ello, precisamente han de ir acompañados de las garantías de objetividad, imparcialidad e independencia» (Cantero, 2011: 69). Por tanto, el resto de quehaceres públicos podría ser externalizado. Esta tesis es la que acoge precisamente el Real Decreto Legislativo 5/2015, de 30 de octubre, por el que se aprueba el texto refundido del Estatuto Básico del Empleado Público (TREBEP), cuyo art. 11.2, por expresa remisión a lo previsto en el art. 9.2, reserva a los funcionarios públicos «el ejercicio de las funciones que impliquen la participación directa o indirecta en el ejercicio de las potestades gubernativas o en la salvaguarda de los intereses generales del Estado y de las Administraciones públicas» (Izquierdo y Molina, 1996: 13). Amplios son, pues, los márgenes de actuación.

\subsection{Los escasos reparos al reclutamiento temporal externo}

Como ya consta, el compromiso de estabilidad presupuestaria y sostenibilidad financiera asumido por el Estado Español como consecuencia de la incorporación al sistema monetario europeo ha incrementado las estadísticas de temporalidad, pues, tal como ha sido alertado por la doctrina, «en no pocas ocasiones, la Administración se ve obligada a recurrir a la externalización como vía de ocultación de la deuda pública que permite el mantenimiento de las exigencias -cada vez mayores- de nuestro Estado de bienestar, lo cual ha provocado una aceleración de los procesos de privatización o gestión indirecta de los servicios públicos por parte de las Administraciones, fruto tanto de las presiones para rebajar el gasto e incrementar la eficacia, como de los movimientos tendentes a reducir la dimensión del sector público» (Rodríguez-Piñero, 2014: 55), sin olvidar el diseño de «cauces más flexibles que los ofrecidos tradicionalmente por el Derecho Administrativo para la satisfacción de los intereses generales. En aras a la consecución de estos objetivos, las Administraciones se han aprovechado de modo recurrente del sistema de contratación pública con una única frontera» (Monero, 2015: 13), marcada por contornos amplios y un tanto borrosos: "en ningún caso podrán prestarse mediante gestión indirecta los servicios que impliquen ejercicio de autoridad inherente a los poderes públicos», términos que se han interpretado en el sentido de no dictar actos administrativos ni ejercitar facultades de autotutela (Parejo, 1989: 23), permitiendo muchas veces recurrir a contratos con empresas

2 STJUE de 3 de junio de 1986, asunto 307/84, Comisión contra Francia. 
que no encajan en la calificación de contrata ex art. 42 Real Decreto Legislativo 2/2015, de 23 de octubre, por el que se aprueba el texto refundido de la Ley del Estatuto de los Trabajadores (ET), sino más bien en el concepto de cesión ilegal de personas trabajadoras prohibida por el art. $43 \mathrm{ET}$, al encontrase perfectamente integradas en la esfera organicista de la entidad pública ${ }^{3}$.

Por ende, permítase la reiteración, «el contrato administrativo con empresas contratistas o concesionarias, que aportan sus medios humanos y materiales a la prestación de la encomienda pública asumida, ha pasado a ocupar un lugar muy destacado en el quehacer de las Administraciones como decisión imprescindible en muchas ocasiones si se quiere lograr la ansiada eficiencia en la dispensa del servicio a favor de los ciudadanos al menor coste posible rebasando incluso los contornos de lo permitido» (Rodríguez, 2010: 13). La propia limitación temporal de los contratos administrativos comporta que los trabajadores al servicio del empresario adjudicatario sean contratados a través de tipologías contractuales de duración determinada, de manera que mediante el recurso a este fenómeno se asiste a una suerte de «sustitución de lo que debería ser empleo de carácter indefinido ligado a la propia Administración por un empleo temporal a través de la empresa privada que se hace cargo de la prestación del servicio público» (Sanguinetti, 2007: 23).

Es más, cabe constatar un curioso fenómeno de reconversión empresarial de antiguas empresas contratistas dedicadas básicamente al contrato de obras públicas, que tiene por objeto la construcción, conservación o mantenimiento de una obra, hacia entidades dedicadas a la gestión integral de contratos públicos, de modo que se han creado organizaciones productivas, o más frecuentemente, grupos de corporaciones multiservicios que se ofrecen como edificadores y gestores omnibus de actividades públicas de todo tipo (desde la limpieza viaria o la recogida de basuras, gestión de residuos, mantenimiento de parques, instalaciones públicas, alumbrado, control de accesos, telefonía y recepción, logística, asistencia técnica, etc.) (Esteve, 2016: 79). Esta vía permite, a la postre, sustituir parcialmente parte del personal propio al servicio de su estructura por su reclutamiento en el mercado, amparada bajo el principio de libertad de empresa, en lugar de recurrir a una ampliación de la relación de plazas vacantes y a la subsiguiente selección de efectivos mediante convocatoria pública y a través del sistema de oposición, concurso-oposición o concurso, previstos legalmente. Pero, en contrapartida, estas empresas actúan como suministradoras de mano de obra proporcionando a la Administración ofertas competitivas basadas en bajos costes laborales. La precariedad laboral alcanza, así, el rango de normalidad.

\subsection{La «pauperización» de las condiciones de trabajo de los asalariados al servicio de contratistas y concesionarios}

La rebaja de los precios de los contratos públicos en los momentos actuales de restricciones presupuestarias va a afectar de manera directa y negativa sobre las condiciones laborales, que se ven perjudicadas, no sólo en la vertiente salarial, sino también en otros aspectos como una mayor inestabilidad en el empleo, un importante incremento de la carga de trabajo o una definición más polivalente de las funciones a realizar, circunstancias que se agravan ante un modelo de selección de contratistas o concesionarios que imponía una clara preferencia por los aspectos económicos. La precarización de las condiciones de este colectivo en aspectos salariales, jornada y carga de trabajo ha venido siendo manifiesta, al igual que el incremento de la siniestralidad, tanto por la mayor presión en el desarrollo de la actividad como por la menor dotación de recursos para la prevención de riesgos laborales, pues el interés empresarial se centrará en conseguir sus objetivos al menor coste posible logrando garantizar un margen de beneficios (Trillo, 2017: 24). De la misma manera, la privatización perjudica la protección colectiva de estos trabajadores, pues, por una parte, van a quedar extramuros del ámbito de actuación participativa de los órganos constituidos en la Administración, y, por otra, por la forma en que prestan sus servicios, las posibilidades de que sean atendidos por los cauces representativos de la empresa adjudicataria también resultan escasas. Ello sin olvidar, como postulado general, que las condiciones laborales aplicables serán las propias de su rama o-casi siempre- de su empresa, por lo común mucho más precarias que las previstas en el convenio colectivo de la Administración matriz para la que indirectamente se trabaja, quedando sometidos a una continua rotación y viendo impedida la generación de antigüedad y la marginada la promoción profesional.

3 Entre las más recientes, SSTS, Social, de 26 de octubre de 2016 (núm. 4941/2016) y 2 de noviembre de 2016 (rec. $2779 / 2014$ ) o STSJ, Social, Andalucía/Málaga de 21 de diciembre de 2016 (rec. 1686/2016). 
Como mal menor, el Tribunal de Justicia de la Unión Europea únicamente ha admitido recientemente, después de muchos pronunciamientos en contra, la posibilidad de obligar a los licitadores a comprometerse a pagar al personal que llevara a cabo las prestaciones objeto del contrato público el salario fijado en el convenio colectivo del lugar de ejecución del contrato (Miranda, 2016: 69)4. Así, en el asunto Regio Post, «el Ayuntamiento de Landau, en el Palatinado alemán, estableció en el contexto de la adjudicación de un contrato público de servicios postales una cláusula por la cual imponía a los licitadores y a sus subcontratistas, pagar un salario mínimo al personal que ejecutase las prestaciones objeto de esa licitación. RegioPost, una de las empresas que concurrió al concurso, consideró que dicha cláusula era ilegal y en su propuesta no respetó su contenido. Obviamente, el Ayuntamiento no la tuvo en cuenta, siendo impugnada ante los Tribunales la decisión municipal. En el curso del litigio, se planteó la cuestión prejudicial, para intentar determinar si la normativa europea era relevante en el caso estudiado, puesto que tanto la autoridad licitadora como la empresa (y las restantes empresas competidoras) se encontraban en Alemania, entendiendo el Tribunal que la exclusión de la licitación que imponía la norma no era gravosa en absoluto» (Toscani y Valenciano, 2016: $89)^{5}$. El salario mínimo venía impuesto por una disposición legal, de conformidad con el art. 3.1 de la Directiva 96/71, de ahí que el Tribunal de Justicia afirmara la compatibilidad de esta previsión sobre salario mínimo con el Derecho Comunitario (Moreno, 2016: 180). Esta doctrina es admitida por el Tribunal Supremo español siempre y cuando dicha cláusula sea establecida por parte de los órganos que tienen competencia para ello $^{6}$. No falta, sin embargo, algún pronunciamiento de suplicación que ha considerado nula la inclusión de una cláusula en los pliegos que fija como parámetro de valoración en un proceso de licitación el compromiso de aplicar el convenio colectivo estatal a efectos salariales, no sólo por no estar directamente relacionado con el objeto del contrato sino porque supone una intromisión en el ámbito de la regulación salarial, no en vano el art. 84.2 ET otorga prioridad aplicativa al convenio de empresa entre otras materias en cuanto a «la cuantía del salario base y de los complementos salariales, incluidos los vinculados a la situación y resultados de la empresa» ${ }^{7}$.

Como anteriormente se apuntó, el carácter amplio del objeto empresarial de las empresas multiservicios que se postulan como posibles adjudicatarias dificulta en muchas ocasiones encuadrar a estas corporaciones en el marco de una concreta regulación convencional sectorial, permitiendo, de algún modo, la selección empresarial de la norma convencional aplicable atendiendo al escurridizo criterio de la actividad preponderante ${ }^{8}$, con el fin último de evitar la aplicación del instrumento paccionado de la empresa cliente, es decir, la Administración Pública comitente. En otros casos, a los trabajadores de las empresas multiservicios se les aplica el convenio colectivo empresarial propio, que, como regla general, va a incorporar condiciones laborales inferiores al de sector.

En materia de Seguridad Social, el retroceso también es claro: la capacidad recaudatoria del sistema es menor por los salarios bajos, de forma que «las cotizaciones más reducidas repercuten en las futuras bases reguladoras y la temporalidad afecta a carreras de cotización que ponen difícil la consecución de los períodos de carencia necesarios para tener derecho a las prestaciones, por no hablar de una protección social complementaria inexistente dada la debilidad negocial» (Rojas, 2018: 283).

\subsection{La inestabilidad laboral inherente}

La precarización no solo alcanza a todas las condiciones laborales, sino que se manifiesta en el mismo momento de acceso al empleo, pues la modalidad habitual de contratación es el vínculo para obra o servicio determinado, justificado en la temporalidad de la contrata. Esta circunstancia lleva a admitir, además, la virtualidad de esta modalidad contractual mientras dure la contrata o concesión ${ }^{9}$, por más que se hayan introducido matices estableciendo que la sucesión de una empresa contratista por otra no extingue sin más el contrato de obra ${ }^{10}$, al igual que tampoco lo hace la rescisión ante tempus de la contrata ${ }^{11}$ y ni siquiera la

\footnotetext{
4 STJUE de 17 de noviembre de 2015.

5 STJCE 115/14, de 17 de noviembre de 2015, asunto RegioPost.

6 STS, Cont-Admtivo, de 31 de mayo de 2016 (rec. 2974/2014).

7 STSJ, Cont.-Admtivo., Madrid de 7 de junio de 2017 (rec. 318/2016)

8 STS, Social, de 17 de marzo de 2015 (rec. 68/2013).

9 STS, Social, de 15 de enero de 1997 (rec. 3827/1995).

10 STS, Social, de 17 de junio de 2008 (rec. 4426/2006).

11 STS, Social, de 28 de abril de 2015 (rec. 1016/2014).
} 
resolución parcial del encargo ${ }^{12}$, pues nada impide, a la postre, utilizar las vías de los arts. 51 y 52 c) ET, asegurando únicamente una indemnización en cuantía de 20 días de salario por año de servicio, muchas veces de montante irrisorio por lo reducido de la base de cálculo y de la exigüidad del tiempo de vinculación. Merece una valoración positiva que el Tribunal Supremo haya considerado que contrato de trabajo por obra o servicio vinculado a una contrata se convierte en indefinido cuando dicha contrata es objeto de sucesivas novaciones, que no meras prórrogas, pues se desnaturalizan tanto la intrínseca temporalidad del vínculo contractual como la sustantividad y autonomía propias características de esta modalidad contractual ${ }^{13}$.

Esta vía contractual ha llegado a convertirse en el cauce ordinario para la ocupación de sujetos adscritos a las empresas adjudicatarias, "provocando un empleo temporal artificial, para una actividad permanente de la Administración, cuya duración se limita como consecuencia de una decisión de la propia entidad pública». Se produce, a la postre, «una clara descausalización de la contratación a término y un ataque directo a la estabilidad en el empleo cercenando cualquier posibilidad de promoción profesional o de consolidación de pluses de antigüedad. Al tiempo, esta vinculación al encargo impide, desviadamente como anomalía jurídica, la normal aplicación del principio legal o convencional de sucesión o subrogación empresarial en los supuestos de cambio de titularidad en contratas o subcontratas» (Monereo, 2007: 309).

Un paso importante a la hora de desligar el contrato por obra o servicio de un proceso de subcontratación viene asociado a la Sentencia del Tribunal de Justicia de la Unión Europea de 14 de septiembre de 2016 (asunto De Diego Porras), pues su doctrina ha sido aplicada también a un supuesto en el que el contrato utilizado ha sido el de obra o servicio determinado en el marco de una contrata, entendiendo que la extinción de este instrumento contractual comporta la obligación de la empresa de abonar al trabajador una indemnización de 20 días de salario por año de servicio, con el máximo de 12 mensualidades, equiparándose así el fin del vínculo para obra y la terminación por razones objetivas de un vínculo indefinido ${ }^{14}$. Ahora bien, no deja de reconocerse una causa automática indemnizada de extinción objetiva de estos contratos ante la resolución anticipada de la contrata, ya sea total o parcial (Vicente, 2018: 280).

Es más -y como motivo de preocupación adicional-, no procede olvidar que el Tribunal de Justicia de la Unión Europea ha vuelto a pronunciarse, ahora en Gran Sala, el 5 de junio de 2018, en los asuntos Montero Mateos y Grupo Norte Facility, cambiando el criterio, entendiendo justificada la diferencia sobre la existencia y cuantía de la indemnización según que la modalidad contractual sea de duración determinada o indefinida. Acoge como postulado para llegar a esta conclusión el factor de «previsibilidad» o "certeza» en cuanto a la finalización de cualquier contrato temporal, circunstancia que no concurre en los contratos de duración indefinida, en los que la extinción debe producirse por una causa no prevista al iniciarse la prestación laboral y que puede ser tanto de índole objetiva como disciplinaria.

Deviene necesaria, pues, la intervención del legislador en aras a reconducir los términos de utilización del contrato por obra o servicio capaz de desvincularlo de los procesos de contratación administrativa.

\subsection{Incremento de la conflictividad colectiva}

La temporalidad y la devaluación generalizada en las condiciones laborales de los asalariados al servicio de las empresas contratistas y concesionarias, acompañada en muchas ocasiones de impagos de salarios y de falta de ingreso de las cotizaciones a la Seguridad Social por los empleadores adjudicatarios, ha generado el surgimiento de numerosos conflictos colectivos, muy mediáticos por afectar a un número muy amplio de usuarios de los servicios públicos, pero la mayoría de las veces poco efectivos desde la perspectiva de las conquistas sociales planteadas, al quedar afectadas in peius «por la des-sindicalización ante la atomización del tejido empresarial y las dificultades de identificación de un interés común» (Monereo, 2018: 271). A ello acompaña una generosa delimitación por la autoridad gubernativa de los servicios mínimos en garantía de los esenciales «a riesgo de convertir el concepto de servicios esenciales en el de servicios públicos» (Baylos, 1988: 2002) que van a seguir operando a ritmo casi normal, olvidando los principios de motivación y de proporcionalidad de sacrificios a sabiendas de que el control judicial siempre llega tarde (Monereo, 2015: 330), máxime si a esto se añade el muy relativo respeto por parte de la autoridad gubernativa de las resoluciones judiciales condenatorias que consideran a posteriori que tales servicios mínimos no debieron

\footnotetext{
12 STS, Social, de 12 de junio de 2008 (rec. 1725/2007).

13 STS, Social, de 19 de julio de 2018 (rec. 823/2017)

14 STSJ, Social, País Vasco, de 18 octubre de 2016 (rec. 1872/2016).
} 
ser fijados o eran excesivos, imponiendo en huelgas posteriores servicios mínimos similares o iguales a los que fueron anulados en su momento (González, 2018: 31).

Otros múltiples factores van a incidir en el escaso éxito de las reivindicaciones, pudiendo mencionar la presión de los ciudadanos que no se conforman con una atención mínima y de peor calidad; la posible dispensa de la actividad descentralizada con medios administrativos propios socavando la prohibición del esquirolaje interno; o el fácil recurso a un arbitraje obligatorio, que se ha utilizado, no sólo ante huelgas especialmente perjudiciales para la economía, caracterizadas por la posición alejada de las partes y la larga duración, sino como técnica de tutela de los usuarios o consumidores ante el incumplimiento de los generosos servicios mínimos (Cordero y Vivero, 2018: 666).

Sin olvidar tampoco que lógicamente el empresario directo tampoco va a soportar estoicamente la huelga, sino que acometerá actuaciones de defensa para tratar de contrarrestar los problemas causados por los huelguistas, máxime cuando pueden derivarse compensaciones económicas o indemnizaciones para los usuarios de los servicios ${ }^{15}$. En este sentido, no es ocioso poner de manifiesto que, en el imaginario empresarial español, el cierre patronal se ha abandonado casi por completo como mecanismo de defensa frente a una huelga (ilegal) y, por el contrario, las estrategias patronales actuales se amoldan mejor a una vertiente utilitarista centrada en el intento claro de mantener la producción (Tascón, 2018: 46). Así, entre los cuantiosos poderes que le corresponden al adjudicatario cuyo ejercicio puede suponer una forma de impedir la huelga, cabe mencionar las advertencias intimidatorias antes del inicio del conflicto, acerca de la supuesta ilegalidad y/o de las consecuencias negativas que pueden derivarse: sanciones, pérdida de contratos con la Administración o con otras empresas o despidos, particularmente los colectivos o por caudas objetivas, justificados en la repercusión de la huelga en la marcha de la corporación con la consiguiente necesidad de supresión de puestos de trabajo ${ }^{16}$.

La escasa posibilidad de impacto del derecho de huelga en este contexto aboca a que gane importancia, en aras a conseguir una más justa redistribución de los réditos de la actividad productiva, la mera exhibición pública del conflicto, conformándose los afectados con otros métodos menos agresivos, normalmente con proporcionar visibilidad y publicidad a la declaración de una huelga futura con un margen de tiempo muy superior a los diez días exigidos, que posteriormente queda diluida ante la dificultad que reviste paralizar efectivamente la actividad laboral dadas las escasas posibilidades de éxito en las reivindicaciones (Grau, 2018, 381).

No obstante estos inconvenientes, lógicamente, los asalariados de las empresas contratistas y concesionarias pueden recurrir a la huelga como medida de presión, de modo que la cesación de la actividad va a repercutir de manera negativa en la Administración comitente. Cierto es que el Tribunal Constitucional, a partir del caso Samoa, ha dejado claro que la huelga en una empresa contratista no puede justificar la rescisión de la encomienda por parte de la principal, pues «de poco servirían las prohibiciones, garantías y tutelas establecidas en la legislación laboral en relación con las actuaciones empresariales lesivas del derecho de huelga si se admitiera que éstas alcanzasen únicamente al contratista, empresario directo de la relación laboral, y no al empresario principal» ${ }^{17}$.

Ahora bien, los recientes pronunciamientos del Tribunal Supremo parecen tener en cuenta, tal y como ha señalado la mejor doctrina, que el hecho de declararse la huelga en la empresa contratista no «constituye un desenlace jurídico por completo ajeno a la empresa principal, con independencia de que los trabajadores realicen o no el trabajo en su centro de trabajo», de modo que cabe plantear «el alcance del deber de soportar la huelga sin adoptar medidas para reducir sus efectos en la esfera patrimonial» (Goerlich, 2018: 189) ${ }^{18}$.

Descartada la obligación de la Administración de negociar con la representación de los huelguistas de una empresa contratista ${ }^{19}$, no hay que olvidar que la LCSP, en su art. 211 , habilita al órgano contratante para resolver la adjudicación atendiendo a dos extremos que podrían resultar de aplicación: «la demora en el cum-

15 Significativo es que la STJUE de 17 de abril de 2018, asuntos acumulados C-195/17, C-203/17, C-228/17, C-274/17, C-275/17, C-278/17 a C-282/17 y C-290/17 a C-292/17, obligue a la empresa a indemnizar a los afectados en caso de cancelación o de gran retraso de un vuelo en un supuesto de «huelga salvaje», carente de previo aviso, del personal de navegación ante el anuncio de unas medidas de reestructuración empresarial.

16 SSTS, Social, de 12 de febrero de 2013 (rec. 254/2011), 20 de septiembre de 2013 (rec. 11/2003) y 18 de julio de 2014 (rec. 11/2013)

17 STCo 75/2010, de 19 de octubre.

18 SSTS, Social, de 16 de noviembre de 2016 (rec. 99/2016), asunto Altrad, 23 de enero de 2017 (rec. 60/2017), asunto contratistas de Telefónica y 13 de julio de 2017 (rec. 25/2017), asunto Indra.

19 SAN, Social, de 28 de octubre de 2015 (rec. 223/2015) y STS, Social, de 23 de enero de 2017 (rec. 60/2016). 
plimiento de los plazos por parte del contratista» y «el incumplimiento de la obligación principal del contrato». Ahora bien, aun cuando el incumplimiento de la empresa contratista o concesionaria de sus compromisos contractuales en caso de huelga vetaría el recurso a estas vías de resolución de la contrata, pues supondría una clara desnaturalización del derecho fundamental, lo cierto es que resultan admisibles otras técnicas más sofisticadas, admitidas por los tribunales de lo contencioso-administrativo, como podría ser «una encomienda de gestión del servicio a una empresa pública ante el incumplimiento de los servicios públicos» ${ }^{20}$.

\section{LAS MEDIDAS CORRECTORAS INTRODUCIDAS POR LA LEY 9/2017. LA APUESTA POR EL PROGRESO EN LAS CONDICIONES DE TRABAJO}

La Organización Internacional del Trabajo (OIT) ha manifestado desde antiguo una clara preocupación para conseguir que en las obras o servicios descentralizados por la Administración hacia empresarios privados se respete la normativa laboral y se ofrezcan condiciones profesionales aceptables a los asalariados ocupados en ellos, pudiendo hacer referencia como más significativos al importante Convenio sobre las cláusulas de trabajo (contratos celebrados por las autoridades públicas), de 1949 (núm. 94), acompañado de la Recomendación núm. 84, de la misma denominación y de la misma anualidad. Parafraseando a la mejor doctrina «para lograr tal objetivo, este Convenio utiliza una técnica jurídica peculiar: en lugar de imponer la obligación de los Estados de establecer en su legislación que los contratistas reconozcan a sus trabajadores salarios y condiciones de trabajo no menos favorables a las del lugar y actividad en cuestión, prevé que la legislación nacional obligue a las Administraciones públicas a incorporar en los contratos administrativos las denominadas cláusulas de trabajo, en virtud de las cuales los contratistas deben comprometerse a reconocer a sus trabajadores salarios, horarios y condiciones de empleo no menos favorables que las establecidas en convenio colectivo, laudo o normativa estatal para un trabajo de igual naturaleza en la misma actividad y en la región donde se ejecute el contrato. Este sistema tiene la ventaja de crear una responsabilidad contractual específica frente a la Administración, garantizada incluso con la posible resolución del contrato, pero tiene el inconveniente de dejar esa obligación a los avatares de la lógica competitiva, factor de debilidad que el tiempo ha acentuado en los sistemas continentales de contratación» (Rodríguez-Piñero, 2005: 5).

A la vista de la Estrategia Europa 2020, que adopta como uno de sus postulados esenciales el de lograr una economía con alto nivel de empleo y cohesión social, la nueva Directiva 2014/24, de 26 de febrero, sobre contratación pública, transpuesta al ordenamiento jurídico español por la Ley 9/2017, de 8 de noviembre, de Contratos del Sector Público (LCSP), adopta, entre sus aspiraciones, el diseño de políticas de progreso de la Unión Europea en materia laboral o social, no en vano hace referencia a los aspectos de esta naturaleza en diversos preceptos relativos a la definición del objeto del contrato (art. 62), en los motivos de exclusión de contratistas (art. 57), en los criterios de adjudicación (art. 67) y en las condiciones de ejecución (art. 70) (Romero, 2017: 127). Esta Directiva afianza la senda hacia la denominada «utilización estratégica de las reglas de la contratación administrativa» o, dicho en otros términos, hacia la «modulación teleológica de las reglas de la contratación pública» (Molina, 2016: 79), postulado de gran importancia atendiendo a las cifras manejadas por la propia Comisión Europea que ponen de manifiesto cómo esta actividad alcanza casi el 20 por 100 del PIB de la Unión. Esta Directiva supone la expresión más reciente en la Unión de la necesidad de que todos los Estados miembros adopten una política más proactiva de orientación social de la compra pública, condicionando el modelo precedente basado casi en exclusiva en la «oferta económicamente más barata» (Molina, 2017: 105). Como ha sentado la doctrina, «ignorar la versatilidad estratégica de la contratación pública supone renunciar al liderazgo institucional que corresponde a los poderes públicos» (Gimeno, 2014: 53) en el ámbito de la descentralización de actividades.

\subsection{La transversalidad de las cláusulas sociales como instrumentos tuitivos de los derechos de los trabajadores}

Con la intención de dar cumplimiento al objetivo de «diseñar un sistema de contratación pública más eficiente, transparente e íntegro, mediante el cual se consiga el mejor cumplimiento de los objetivos públicos, tanto a través de la satisfacción de las necesidades de los órganos de contratación, como mediante una me-

20 STSJ, Cont.-Admtivo., Madrid, de 2 de junio de 2015 (rec. 306/2015). 
jora de las condiciones de acceso y participación en las licitaciones públicas de los operadores económicos y, por supuesto, a través de la prestación de mejores servicios a los usuarios de los mismos» (Pintos, 2017, 3), el art. 1.3 LCSP prevé que «en toda contratación pública se incorporarán de manera transversal y preceptiva criterios sociales (y medioambientales) siempre que guarden relación con el objeto del contrato», «en la convicción de que su inclusión proporciona una mejor relación calidad-precio en la prestación contractual, así como una mayor y mejor eficiencia en la utilización de los fondos públicos, facilitando, al tiempo, el acceso a la contratación pública de las pequeñas y medianas empresas, así como de las empresas de economía social» (Larrazabal, 2017: 151), sin olvidar afianzar el cumplimiento de la "garantía de la libre concurrencia, pues evita que los licitadores busquen el incumplimiento de las condiciones laborales como medio para reducir costes» (Ferrando y Rodríguez, 2017: 236), objetivo este último a salvaguardar por la "Comisión Interministerial para la incorporación de criterios sociales en la contratación pública» (Real Decreto 94/2018, de 2 de marzo) (Larrazabal, 2016: 310).

Buena muestra de tan amplio propósito de aplicación transversal de condiciones sociales en todo el proceso de contratación puede encontrarse en el art. 122.2 LCSP que exige «la introducción en los pliegos de cláusulas administrativas particulares», definidores de la dinámica de la relación contractual pergeñando las prerrogativas y obligaciones de cada una de las partes, de «las consideraciones sociales, laborales y ambientales que como criterios de solvencia, de adjudicación o como condiciones especiales de ejecución se establezcan», en referencia, por tanto, a todas las fases que integran el proceso de contratación: preparación, adjudicación y ejecución.

\subsection{La exclusión de ofertas anormalmente bajas: el cumplimiento de los convenios sectoriales en cuanto a condiciones salariales se refiere}

La Ley 9/2017 introduce una regulación más estricta en cuanto al rechazo de las ofertas anormalmente bajas, pues el art. 149.4 deja claro que, en todo caso, «los órganos de contratación rechazarán aquellas propuestas que no cumplen la normativa sobre subcontratación o las obligaciones aplicables en materia social o laboral, nacional o internacional, incluyendo el incumplimiento de los convenios colectivos sectoriales vigentes, en aplicación de lo establecido en el artículo 201». Sin embargo, no se entiende por qué, marginando otro tipo de normas internacionales, el art. 201 remite a un listado tasado de convenios de la OIT, cuales son los siguientes: «núm. 87, sobre la libertad sindical y la protección del derecho de sindicación, núm. 98, sobre el derecho de sindicación y de negociación colectiva, núm. 29, sobre el trabajo forzoso, núm. 105, sobre la abolición del trabajo forzoso, núm. 138, sobre la edad mínima, núm. 111, sobre la discriminación (empleo y ocupación), núm. 100, sobre igualdad de remuneración o núm. 182, sobre las peores formas de trabajo infantil». La única explicación posible podría encontrarse en la selección de convenios realizada por la «Declaración de la OIT relativa a los principios y derechos fundamentales en el trabajo y su seguimiento de 1998», pues entiende que tales instrumentos se aplican a la generalidad de los ciudadanos en todos los territorios.

Asimismo, sorprende la referencia expresa al incumplimiento del convenio colectivo sectorial, alterando el sistema de fuentes establecido en el ET, en virtud del cual, en determinadas materias el pacto colectivo de empresa tiene prioridad aplicativa sobre el sectorial, a saber: «a) La cuantía del salario base y de los complementos salariales, incluidos los vinculados a la situación y resultados de la empresa. b) El abono o la compensación de las horas extraordinarias y la retribución específica del trabajo a turnos. c) El horario y la distribución del tiempo de trabajo, el régimen de trabajo a turnos y la planificación anual de las vacaciones. d) La adaptación al ámbito de la empresa del sistema de clasificación profesional de los trabajadores. e) La adaptación de los aspectos de las modalidades de contratación que se atribuyen por esta ley a los convenios de empresa. f) Las medidas para favorecer la conciliación entre la vida laboral, familiar y personal. g) Aquellas otras que dispongan los acuerdos y convenios colectivos a que se refiere el artículo 83.2» (art. 84.2 ET) (Pérez y Zambonino, 2008: 52).

Merece, no obstante, una valoración muy positiva la mención explícita de tales convenios sectoriales $y$, por tanto, su obligatorio respeto con independencia de la existencia de un convenio de empresa, pues en muchas ocasiones los convenios de empresa se han hecho para, tras un descuelgue, reducir de manera importante las condiciones laborales esenciales de los asalariados, principalmente las salariales. Con esta previsión parece que se termina con las dudas que planteaba, en paradigmático ejemplo, la incorporación de previsiones garantistas de este tipo en algunas disposiciones forales en relación con contratos administrativos de obra, respecto de las cuales la Sala de lo Contencioso-Administrativo del Tribunal Supremo había 
considerado necesaria la intervención del legislador (Larrazabal, 2015: 125) ${ }^{21}$. El paso dado por la LCSP ha sido importante en aras a garantizar la transparencia y a evitar la precarización de las circunstancias laborales de los asalariados privados que prestan servicios públicos, pero la lectura puede que no sea tan positiva si se tiene en cuenta que la exigencia de que el convenio sectorial esté «vigente» puede evitar su aplicación si ha sido desplazado, en las materias que prevé el art. 84.2 ET, por un convenio de empresa.

\subsection{Presupuesto base de la licitación}

Al fin de garantizar los salarios de los trabajadores, contribuye también la exigencia de «desglose en el presupuesto base de licitación (esto es, el límite máximo de gasto que en virtud del contrato puede comprometer el órgano de contratación), indicando en el pliego de cláusulas administrativas particulares o documento regulador de la licitación los costes directos e indirectos y otros eventuales gastos calculados para su determinación. En los contratos donde el coste de los salarios de las personas empleadas para su ejecución formen parte del precio total, el presupuesto base de licitación indicará de forma desglosada y con desagregación de género y categoría profesional los costes salariales estimados a partir del convenio laboral de referencia» (art. 100 LCSP).

Asimismo, «en el cálculo del valor estimado de los contratos deberán tenerse en cuenta, como mínimo, además de los costes derivados de la aplicación de las normativas laborales vigentes, otros costes que se deriven de la ejecución material de los servicios, los gastos generales de estructura y el beneficio industrial... En los contratos de servicios y de concesión de servicios en los que sea relevante la mano de obra, en la aplicación de la normativa laboral vigente a que se refiere el párrafo anterior se tendrán especialmente en cuenta los costes laborales derivados de los convenios colectivos sectoriales de aplicación» (art. 101 LCSP). Igualmente, la previsión que sienta que «en aquellos servicios en los que el coste económico principal sean los costes laborales, deberán considerarse los términos económicos de los convenios colectivos sectoriales, nacionales, autonómicos y provinciales aplicables en el lugar de prestación de los servicios» (art. 102.3) (Marcos, 2015: 108).

\subsection{Condiciones especiales de ejecución}

«La posibilidad de supeditar las adjudicaciones de los contratos públicos a la colaboración del adjudicatario en determinadas políticas sociales se muestra ya con claridad en el Libro Verde de la Contratación Pública de la Unión Europea» ${ }^{22}$, el cual en su apartado 5.42 establece «la imposición, como condición de ejecución de los contratos administrativos adjudicados, del respeto de las obligaciones de carácter social, encaminadas, por ejemplo, a fomentar el empleo de las mujeres o a favorecer la protección de determinadas categorías desfavorecidas» (Pérez, 2006: 29). Los poderes adjudicadores «pueden imponer al titular del contrato la observancia de cláusulas contractuales relativas a la forma de ejecución del mismo que sean compatibles con el Derecho Comunitario. Estas cláusulas pueden englobar medidas laborales a favor de determinadas categorías de personas y actuaciones positivas en materia de empleo» (Vázquez, 2016: 28).

Con las posibilidades que marca la Directiva 2014/24, el art. 35.1 n) LCSP incluye entre las previsiones expresas que debe de incluir el documento en que se formalice el vínculo público correspondiente, una vez adjudicado, la relativa a «la obligación de la empresa contratista de cumplir durante todo el período de ejecución del contrato las normas y condiciones fijadas en el convenio de aplicación». En una primera aproximación, se podría cuestionar la pertinencia u oportunidad de incorporar este apartado que no es sino un recordatorio de una obligación que ya recae sobre el empresario contratista en virtud del ordenamiento jurídico laboral vigente y que debiera resultar indisponible para las partes al formalizar el contrato administrativo, si bien no debe soslayarse la importante seguridad jurídica que incorpora para los trabajadores de las empresas adjudicatarias, máxime cuando el art. 122.2 LCSP recoge expresamente la inclusión en «los pliegos de cláusulas de condiciones administrativas» de «la obligación del adjudicatario de cumplir las condiciones salariales de los trabajadores conforme al convenio colectivo sectorial de aplicación ${ }^{23}$, de manera que mientras dure el contrato público se ha de entender que el empresario tendrá vedado el poder recurrir a

\footnotetext{
21 SSTS, Cont.-Admtivo., de 23 mayo, 31 mayo y 2 de junio de 2016 (rec. 1383/2015, 1242/2016 y 852/2015).

22 DOCE C-374E, de 28 de diciembre de 2000.

23 En línea con la STJCE 115/14, de 17 de noviembre de 2015, asunto RegioPost.
} 
los mecanismos que la legislación laboral actual reconoce para poder inaplicar lo dispuesto en materia retributiva en una norma paccionada de ámbito superior a la empresa, esto es, al descuelgue de las condiciones salariales previstas o a la aplicación prioritaria de lo dispuesto en el convenio de empresa respecto a otro de ámbito superior. Se está corrigiendo, al menos en el ámbito de la contratación administrativa, una de las aportaciones sustanciales de la reforma laboral de 2012, a saber, la prioridad aplicativa de los pactos colectivos de empresa sobre los convenios de sector, en los términos previstos en el art. $84 \mathrm{ET}$, al venir obligadas las empresas licitadoras a satisfacer, en todo caso, los salarios (previsiblemente superiores) del convenio sectorial correspondiente a la actividad externalizada como medida para dignificar las circunstancias de trabajo de los trabajadores adscritos a la contrata y evitar estrategias de licitación a la baja a base de reducir costes laborales con grave distorsión de la competencia (Cavas, 2017: 271). En efecto, se evita así que las corporaciones participantes en los procedimientos de contratación pública puedan incurrir en competencia desleal respecto a otras ofreciendo propuestas económicamente más favorables para la Administración mediante la reducción de los costes salariales posibilitada por la inaplicabilidad de lo dispuesto en el convenio sectorial, práctica habitual hasta ahora de la mano de las empresas multiservicio (Martín, 2018: 110). Con esta regulación se pone fin a la polémica anterior, pues tal exigencia había venido siendo admitida por el TACP de Madrid ${ }^{24}$, pero fue anulada por la sala de lo contencioso-administrativo del Tribunal Superior de Justicia de Madrid en sentencia de 7 de junio de $2017^{25}$.

Además, el art. 202 LCSP establece, al igual que su precedente, la posibilidad de que «los órganos de contratación establezcan condiciones especiales en relación con la ejecución del contrato, siempre que estén vinculadas al objeto del contrato, no sean directa o indirectamente discriminatorias, sean compatibles con el Derecho Comunitario y se indiquen en el anuncio de licitación y en los pliegos ${ }^{26}$.

Esta exigencia de vinculación al objeto de contrato añade un condicionante que limitará el juego de estas condiciones (Gala, 2010: 27), pero que viene exigido por el considerando 98 de la Directiva 24/2014, debiendo ser entendido en los generosos términos que marca la propia LCSP en su art. 145: «cuando se refiera o integre las prestaciones que deban realizarse en virtud de dicho contrato, en cualquiera de sus aspectos y en cualquier etapa de su ciclo de vida, incluidos los factores que intervienen en los siguientes procesos: a) en el proceso específico de producción, prestación o comercialización de, en su caso, las obras, los suministros o los servicios, con especial referencia a formas de producción, prestación o comercialización medioambiental y socialmente sostenibles y justas; b) o en el proceso específico de otra etapa de su ciclo de vida, incluso cuando dichos factores no formen parte de su sustancia material» (Vallecillo, 2017: 193).

A cambio, el actual art. 202 LCSP establece la obligación de incluir en el pliego de cláusulas administrativas particulares, al menos, una de las condiciones especiales de ejecución siguientes enunciadas en un listado abierto que se transcribe literalmente: «hacer efectivos los derechos reconocidos en la Convención de las Naciones Unidas sobre los derechos de las personas con discapacidad; contratar un número de personas con discapacidad superior al que exige la legislación nacional; promover el empleo de personas con especiales dificultades de inserción en el mercado laboral, en particular de las personas con discapacidad o en situación o riesgo de exclusión social a través de empresas de inserción; eliminar las desigualdades entre el hombre y la mujer en dicho mercado, favoreciendo la aplicación de medidas que fomenten la igualdad entre mujeres y hombres en el trabajo; favorecer la mayor participación de la mujer en el mercado laboral y la conciliación del trabajo y la vida familiar; combatir el paro, en particular el juvenil, el que afecta a las mujeres y el de larga duración; favorecer la formación en el lugar de trabajo; garantizar la seguridad y la protección de la salud en el lugar de trabajo y el cumplimiento de los convenios colectivos sectoriales y territoriales aplicables; medidas para prevenir la siniestralidad laboral; otras finalidades que se establezcan con referencia a la

24 Resoluciones de 3 de febrero de 2016, 6 de octubre de 2016, 18 de enero de 2017, 1 de febrero de 2017 y 18 de julio de 2017.

25 Rec. 318/2016.

${ }^{26}$ Antes de la actual LCSP, el Informe 16/2014 de la Junta Consultiva de Contratación Administrativa de Aragón ha llegado a la conclusión de que «la inclusión en los pliegos de cláusulas administrativas particulares de una condición especial de ejecución en virtud de la cual se obligue a las empresas adjudicatarias a no minorar las condiciones de trabajo (jornada, salario y mejoras sobre la legislación laboral básica) de los trabajadores adscritos al contrato en el que se incorpora la misma, en función del convenio colectivo que resulte de aplicación al presentarse la oferta, no vulnera el ordenamiento jurídico español ni el Derecho de la Unión Europea siempre que no sea discriminatoria y se respete el principio de publicidad». Sin embargo, la Resolución núm. 160/2016 del Tribunal Administrativo Central de Recursos Contractuales consideró inadmisibles las siguientes condiciones especiales de ejecución por condicionar el poder de dirección del empresario: «cualquier modificación sustancial de las condiciones de trabajo requerirá conformidad previa por parte del Alcalde; en el caso de declaración judicial de despido improcedente, procede de forma forzosa la readmisión, salvo que el afectado optara por la indemnización, previa aprobación por el Pleno; para un mejor control de los trabajadores, la empresa adjudicataria intentará dentro de los posible la adscripción de los trabajadores en los ámbitos de las dependencias municipales y colegios». 
estrategia coordinada para el empleo, definida en el artículo 145 del Tratado de Funcionamiento de la Unión Europea (potenciar una mano de obra cualificada, formada y adaptable y mercados laborales con capacidad de respuesta al cambio económico); o garantizar el respeto a los derechos laborales básicos a lo largo de la cadena de producción mediante la exigencia del cumplimiento de las Convenciones fundamentales de la Organización Internacional del Trabajo, incluidas aquellas consideraciones que busquen favorecer a los pequeños productores de países en desarrollo, con los que se mantienen relaciones comerciales que les son favorables tales como el pago de un precio mínimo y una prima a los productores o una mayor transparencia y trazabilidad de toda la cadena comercial».

El art. 202.4 LCSP añade, como novedad, que «todas las condiciones especiales de ejecución que formen parte del contrato serán exigidas igualmente a todos los subcontratistas que participen de la ejecución del mismo, exigencia que evitará la precarización de las condiciones de trabajo en las cadenas de subcontratación».

Conviene tener presente también que el art. 202 LCSP es aplicable, a tenor del art. 319.1 LCSP, «a los efectos y extinción de los contratos celebrados también por los poderes adjudicadores no pertenecientes a la categoría de Administraciones públicas, como excepción a la aplicación de las reglas de derecho privado (fundaciones públicas, mutuas, entidades públicas empresariales, sociedades mercantiles públicas, fondos sin personalidad jurídica o entidades con personalidad jurídica propia, que hayan sido creadas específicamente para satisfacer necesidades de interés general que no tengan carácter industrial o mercantil, siempre que uno o varios sujetos pertenecientes al sector público financien mayoritariamente su actividad, controlen su gestión, o nombren a más de la mitad de los miembros de su órgano de administración, dirección o vigilancia, partidos políticos, organizaciones sindicales y empresariales, así como las fundaciones y asociaciones vinculadas a cualquiera de ellos siempre que se cumplan determinadas circunstancias como que su financiación sea mayoritariamente pública, u otro tipo de asociaciones de carácter público)».

\subsection{Posible resolución del contrato administrativo por impagos salariales}

El nuevo art. 211 LCSP incluye como garantía de los derechos laborales una nueva causa de resolución del contrato en su apartado i) cual es «el impago, durante la ejecución del contrato, de los salarios por parte del contratista a los trabajadores que estuvieran participando en la misma», o "el incumplimiento de las condiciones establecidas en los convenios colectivos en vigor para estos trabajadores también durante la ejecución del contrato».

El art. 212 LCSP aclara que «la resolución del contrato se acordará por el órgano de contratación, de oficio o a instancia del contratista, en su caso, siguiendo el procedimiento que en las normas de desarrollo de esta Ley se establezca. No obstante lo anterior, la resolución del contrato por la causa a que se refiere la letra i) del artículo 211.1 solo se acordará, con carácter general, a instancia de los representantes de los trabajadores en la empresa contratista; excepto cuando los trabajadores afectados por el impago de salarios sean trabajadores en los que procediera la subrogación de conformidad con el artículo 130 y el importe de los salarios adeudados por la empresa contratista supere el 5 por ciento del precio de adjudicación del contrato, en cuyo caso la resolución podrá ser acordada directamente por el órgano de contratación de oficio».

\section{EL OLVIDO DE LOS PELIGROS LABORALES DERIVADOS DEL ENCADENAMIENTO DE CONTRATAS}

Pese a todos estos avances en cuanto a la calidad en el empleo hace, es menester parar la atención en un supuesto todavía desprotegido, derivado de la subcontratación sucesiva de una adjudicación inicial. Cierto es que, como ha señalado la doctrina, «cuando la Administración comitente y el empresario adjudicatario celebran un contrato administrativo, su ejecución supone disponer la organización de medios materiales y humanos del segundo al servicio de la primera por razón de ese encargo, de modo que el objeto del contrato celebrado entre ambos sujetos conlleva la puesta en funcionamiento de la organización productiva del mencionado empresario, elegido por la Administración tras un proceso reglado, como parte accidental del ciclo de actuación de la Administración» (Manteca, 2005: 33). Tal postulado no impide, empero, que la sustitución en parte del licitador que ha conseguido el contrato administrativo, llevada a cabo a través del instrumento de la subcontratación, sea una realidad en ascenso. Es harto frecuente que los titulares de los nexos públicos acudan a colaboradores, asumiendo estos últimos la cualidad de «empleadores principales» de otros a efectos laborales. 


\subsection{La admisibilidad de la subcontratación como postulado de la legislación administrativa}

Teniendo en cuenta que el adjudicatario no es sustituido en su emplazamiento y vinculación respecto de la Administración, la legislación contractual pública adopta un criterio flexible, admitiendo sin ambages el recurso a la subcontratación, no en vano no concurriendo suplantación total del adjudicatario, no se altera la naturaleza jurídica del encargo.

El art. 215 LCSP pergeña unos tímidos requisitos: «no se precisa y, por ende, no es obligatoria, la previa autorización expresa del órgano de contratación (salvo para aquellos contratos de carácter secreto o reservado, en aquellos cuya ejecución deba de ir acompañada de medidas de seguridad especiales o cuando lo exija la protección de los intereses esenciales de la seguridad del Estado); antes al contrario, únicamente es necesario para ello comunicar anticipadamente y por escrito a la Administración la intención de celebrar los subcontratos, señalando la parte de la prestación que se pretende subcontratar y -cómo no- la identidad del subcontratista, justificando, al tiempo, suficientemente la aptitud de éste para ejecutarla por referencia a los elementos técnicos y humanos de que dispone y a su experiencia. En ningún caso podrá concertarse con el contratista la ejecución parcial del contrato con personas inhabilitadas para contratar o afectadas por alguna causa de prohibición» (Rodríguez, 2010: 43).

\subsection{Imputabilidad global frente a la Administración del adjudicatario inicial a la luz de la Ley de Contratos del Sector Público}

En aras a garantizar la probidad del vínculo contractual público, la nueva Ley no se opone al recurso de la subcontratación; solamente exige, además de la observancia de las aludidas formalidades, algunos vetos que pretenden garantizar la imputabilidad global del empleador beneficiario ab initio. En los claros términos del art. 215, «el contratista principal -es decir, el adjudicatario- continúa obligado a todos los efectos ante el poder adjudicador y el subcontratista queda obligado sólo ante el contratista principal. De esta diferenciación obligacional, cabe inferir la existencia de dos contratos perfectamente distintos: uno, de naturaleza pública, es decir, el del poder adjudicador con el agente adjudicatario, y, otro, de naturaleza privada, esto es, entre este último y un nuevo empresario, de lo que se deduce que la subcontratación no implica la existencia de una tercera parte en el contrato público, sino únicamente una relación jurídica y económica entre el adjudicatario y el subcontratista ajena a la relación principal entre el poder adjudicador y el primero» (Rodríguez, 2010: 44).

Ahora bien, tal disimilitud, operativa desde el tenor legal, no siempre está tan aquilatada en la realidad, máxime cuando entra en juego una posible responsabilidad en materia laboral, pese a que según el art. 215.4 LCSP «los subcontratistas quedarán obligados solo ante el contratista principal que asumirá, por tanto, la total responsabilidad de la ejecución del contrato frente a la Administración, con arreglo estricto a los pliegos de cláusulas administrativas particulares o documento descriptivo, y a los términos del contrato, incluido el cumplimiento de las obligaciones en materia... social o laboral».

Como no podía ser de otra manera, estas reglas de contratación pública se deben de combinar con otras laborales, singularmente con lo previsto en el art. $42 \mathrm{ET}$, «que no parte de una consideración ilegal o patológica de la descentralización, sino de su licitud, pero sin perder de vista cómo tal fenómeno puede provocar un desplazamiento de responsabilidades empresariales capaz de perjudicar la efectividad de los derechos de los trabajadores» (Mercader, 2018: 208), se detiene en establecer una serie de cautelas que compaginan mal con la ordenación administrativa anteriormente transcrita.

\subsection{Las responsabilidades desde el punto de vista del lus Laborum}

La doctrina científica ha admitido y continúa admitiendo la aplicación del régimen jurídico previsto en el art. 42 ET al ámbito de los contratos del sector público (Nores, 2004: 37), en especial, «tras una serie de sentencias en las que de forma expresa se reconoce la aplicabilidad de este principio en el ámbito de las Administraciones públicas, no en vano el término contratas y subcontratas utilizado por el art. 42 ET tiene un marcado carácter atécnico» (Cruz, 1992: 114). Utilizando palabras del propio Tribunal Supremo, «el área prestacional y no económica en que son encuadrables las obras o servicios públicos encomendados por las Administraciones a quienes son empleadores directos de los trabajadores, efectuados mediante contratación administrativa, no excluye por la condición pública del titular de las obras o servicios, la aplicación del art. $42 \mathrm{ET}$, dado que dicha cualidad no es obstáculo para que tales entidades, de haber asumido directamen- 
te y por sí mismas la gestión de las referidas obras o servicios, con los que atienden a la consecución de los fines enmarcados en el área de su competencia, hubieran actuado como empleadores directos» ${ }^{27}$.

Sea como fuere, lo cierto es que la Ley laboral establece una serie de garantías en beneficio de los asalariados, fundadas en el esbozo de un entramado de responsabilidades que alcanzan incluso a la empresa principal para el supuesto de incumplimiento por parte de las empresas colaboradoras de sus obligaciones laborales.

Chocan, pues, dos ordenamientos inspirados en principios distintos: de un lado, el lus Laborum, muy restrictivo, cuyo objetivo principal no es otro que el de proteger a los asalariados y al sistema público de Seguridad Social de la insolvencia de los empresarios contratistas y subcontratistas involucrados en una cadena de subcontratación de concesiones administrativas; de otro, el administrativo, mucho más permisivo, pues admite con normalidad la subcontratación, «preocupándose únicamente de garantizar la continuidad en la prestación del servicio público y de establecer cautelas únicamente tendentes a evitar los supuestos más extremos consistentes en la existencia de concesionarios exclusivamente dedicados a la captación de contratos y a su posterior intermediación con los contratistas reales, haciendo peligrar la eficiencia en la prestación del servicio en perjuicio de los usuarios» (Rodríguez, 2006: 26).

\subsection{El limitado juego del principio de solidaridad empresarial}

En un primer acercamiento, el sistema jurídico laboral no introduce restricción alguna que impida al adjudicatario, en uso de su libertad de empresa constitucionalmente proclamada por el art. 38 CE y de su poder de organización (art. $20 \mathrm{ET}$ ), recurrir a la colaboración externa para completar su actividad productiva. Ahora bien, con el fin último de erradicar el riesgo de fraudes y de transgresiones laborales que cualquier técnica de outsourcing puede llevar aparejados, toda vez que la simultaneidad de varios empleadores hace más fácil la elusión de deberes y responsabilidades, no puede extrañar que la ley laboral se esfuerce en establecer una serie de precauciones o salvaguardas en beneficio de los trabajadores, agrandadas en muchos casos por una generosa interpretación de los órganos judiciales, que no han impedido, empero, el incremento de los ratios de empleo a término ni el surgimiento de subterfugios para eludir pagos salariales y cotizaciones a la Seguridad Social.

Como no podía ser de otra manera, el entramado de responsabilidad administrativa diseñado desde la LCSP no implica, sin embargo, que los derechos de los asalariados inmersos en el proceso de externalización queden ayunos de protección, pues la aplicación del art. 42.2 ET deja clara la existencia de una «responsabilidad solidaria durante el año siguiente a la terminación del encargo entre la Administración, el contratista y los subcontratistas por las deudas salariales contraídas por estos últimos con sus empleados». Además, y «durante los tres años siguientes a la terminación de su encargo, el empresario principal (la Administración, in casu) responderá solidariamente de las obligaciones referidas a la Seguridad Social contraídas por los contratistas y subcontratistas». En ambos casos, se trata de débitos generados durante la vigencia de la contrata.

De la presente regulación social se infiere que la corporación comitente o principal «responde solidariamente de las obligaciones salariales y de la Seguridad Social contraídas por los contratistas y subcontratistas con sus trabajadores no porque ostente la posición de empleadora respecto de éstos, sino porque el legislador le ha atribuido el papel de avalista o garante legal del cumplimiento de dichas obligaciones. Por tanto, la responsabilidad alcanzará a la Administración o, en términos más generales, a todos los empresarios implicados en la cadena de contratas y subcontratas respecto de las obligaciones de los empresarios sucesivos» ${ }^{28}$.

Como ha señalado el Tribunal Supremo, «sin duda el art. 42 ET no fue redactado pensando en el ámbito contractual público, pero pretender en todo caso la exoneración de responsabilidad de la Administración comitente alegando que su actividad de fomento no entraña ejercicio de actividad empresarial, supone un trato diferenciado carente de justificación frente al sector privado y una discriminación con efectos previsiblemente negativos para los trabajadores de los empresarios con quienes contrate. Así, a la Administración le debe alcanzar la responsabilidad en materia laboral y de Seguridad Social por los hechos o actos del concesionario-gestor, incluso cuando éste entre en relaciones de derecho privado..., (de modo que) ésta

27 STS, Social, de 15 de julio de 1996 (rec. 1089/1996). También, SSTS, Social, de 18 de marzo de 1997 (rec. $3090 / 1996)$ y 29 de octubre de 1998 (rec 1213/1998).

28 STS, Social, de 9 de julio de 2002 (rec. 2175/2001). 
no puede desentenderse de ninguna manera de los daños que cause la actuación del adjudicatario o las empresas auxiliares con las que éste subcontrate parcelas de la prestación del servicio público asumido» ${ }^{29}$.

Doble proyección presenta esta responsabilidad: por un lado, sobre las «obligaciones de naturaleza salarial contraídas por los contratistas y subcontratistas con sus trabajadores», incluyendo las deudas salariales sin limitación en su importe pero no cualquier otra (percepciones extrasalariales, salarios de tramitación o indemnizaciones por terminación del contrato) ${ }^{30}$; por otro, sobre las «obligaciones referidas a la Seguridad Social contraídas por los contratistas y subcontratistas durante el período de vigencia de la contrata», afectando a los «descubiertos por cuotas impagadas y a las prestaciones de las que hubiera sido declarado responsable el contratista o subcontratista por falta de afiliación alta o cotización, pero no a las mejoras voluntarias» (arts. 165 y 167 Real Decreto Legislativo 8/2015, de 30 de octubre, por el que se aprueba el testo refundido de la Ley General de Seguridad Social (TRLGSS)] ${ }^{31}$.

\subsection{El concepto "propia actividad» como requisito sine qua non para generar la corresponsabilidad}

La apuesta por la garantía solidaria acogida por el art. 42 ET, de aplicación también a los supuestos de externalización de contratos administrativos, queda supeditada a la concurrencia de una exigencia sine qua non: «que el objeto de la contrata o concesión administrativa pertenezca a la propia actividad» de la Administración comitente, «concepto jurídico harto problemático, pues la frontera entre lo principal y lo accesorio no siempre resulta nítida ni mucho menos generalizable, máxime cuando las Administraciones públicas no realizan una sola o preferente actividad sino una pluralidad de ellas, consecuencia a su vez de la multiplicidad de funciones y ámbitos de actuación asignados a su competencia» (Rodríguez, 2010: 50).

La mayor parte de las resoluciones judiciales vienen atendiendo al "criterio del ciclo productivo», esto es, aquellas operaciones, tareas o labores que son inherentes a la producción de los bienes o servicios específicos que se dispensan al público o se colocan en el mercado, de suerte que prácticamente dicho parámetro equivale a la misma actividad, quedando extramuros de los efectos del art. 42 ET todas aquellas contratas de obras o servicios en los que la empresa principal y los contratistas se dedican a cometidos diferentes, de tal forma que, de no haberse suscrito la contrata, los cometidos deberían llevarse a cabo por el propio empleador comitente so pena de soslayar sensiblemente su actividad empresarial y los réditos inherentes $^{32}$. Aplicando esta doctrina general a una encomienda pública, habrá que «considerar cómo aquellas actividades que respondiesen a las previsiones fijadas en la normativa específica que reparte y atribuye las funciones y competencias de las diferentes entidades administrativas formarían parte del concepto propia actividad y, en consecuencia, caso de proceder a su contrata, sería de aplicación el mecanismo de la responsabilidad solidaria entre Administración comitente, contratista y subcontratista, siempre y cuando el destinatario último fuera el ciudadano, es decir, su finalidad fuera la satisfacción del interés general» ${ }^{33}$.

No obstante, el casuismo existente en vía judicial es muy marcado. Buena muestra de tal inseguridad jurídica en la interpretación del concepto «propia actividad» en el marco contractual público, es menester destacar cómo con tal propósito se ha incluido dentro de este postulado: «el servicio de retirada de vehículos mal aparcados» ${ }^{34}$, «la limpieza y mantenimiento de los jardines públicos» ${ }^{35}$, «ciertas tareas de vigilancia» ${ }^{36}$, «el mantenimiento de una estación depuradora de aguas» ${ }^{37}$, «la urbanización de determinadas parcelas de un polígono industrial» ${ }^{38}$, «el ensanche y saneamiento de un camino vecinal» ${ }^{39}$, «la reurbanización de una calle ${ }^{40}$, «la explotación de un teatro perteneciente a un ente autonómico» ${ }^{41}$, «la gestión del servicio

29 STS, Social, de 18 de marzo de 1997 (rec. 3090/1996).

30 SSTSJ, Social, Castilla-La Mancha, de 25 de octubre de 2013 (rec. 13/2012) y Castilla y León, de 27 de julio de 2016 (rec. 388/2016)

${ }_{31}$ STSJ, Social, Extremadura, de 22 de septiembre de 2015 (rec. 342/2015).

32 STS, Social, de 18 de enero de 1995 (rec. 150/1994) y 22 de noviembre de 2002 (rec. 3904/2001).

33 SSTS, Social, de 18 de enero de 1995 (RJ 1995, 514) y 15 de julio de 1996 (RJ 1996, 5990).

34 STSJ, Social, Andalucía/Málaga, de 24 de diciembre de 1999 (AS 1999, 4356).

35 SSTSJ, Social, Andalucía/Málaga, de 9 de febrero y 9 de marzo de 1998 (AS 1998, 1242 y 1805).

36 STS, Social, de 18 de enero de 1995 (RJ 1995, 514).

37 STSJ, Social, País Vasco, de 17 de febrero de 1998 (AS 1998, 759).

38 STSJ, Social, Andalucía, de 3 de noviembre de 1998 (rec. 668/1998).

39 SSTSJ, Social, Galicia, de 4 de diciembre de 2008 (rec. 112/2006) y 20 de enero de 2014 (rec. $4749 / 2011$ ).

40 STSJ, Social, Valencia, de 3 de julio de 2012 (rec. 63/2012).

41 STSJ, Social, Madrid, de 27 de enero de 1999 (AS 1999, 96). 
de cuidado de minusválidos psíquicos profundos» ${ }^{42}$, «la atención a personas mayores en centros de día» ${ }^{43}$ o «en residencias» ${ }^{44}$, «la adjudicación administrativa de comedores escolares» ${ }^{45}$, «el servicio de vigilancia o socorrismo en las playas» ${ }^{46}$, «la toma de datos para la informatización de un servicio» ${ }^{47}$, «el transporte sanitario ordinario por parte de un ente autonómico de salud» ${ }^{48}$, «la limpieza del fondo del depósito de una depuradora ${ }^{49}$, «la gestión de un centro de atención a ancianos» ${ }^{50} \mathrm{O}$ «la gestión integral del ciclo hídrico por parte de un Ayuntamiento» ${ }^{51}$.

Sin embargo, se ha excluido del marco objetivo del tenor aquí manejado: «la apertura y cierre de los edificios e instalaciones» ${ }^{52}$, «la explotación de un servicio de cafetería en un hospital» ${ }^{53}$, «la contrata suscrita por una Consejería para efectuar una mudanza» ${ }^{54}$, «la grabación de datos nominales de trabajadores (TC1 y TC2) correspondientes a un determinado período» ${ }^{55}$, «las obras de construcción y remodelación de un edificio contratadas por una Comunidad Autónoma» ${ }^{56}$, «la prestación de servicios de seguridad o vigilancia en edificios públicos» ${ }^{57}$, «la limpieza de los entes docentes públicos de una ciudad» ${ }^{58}$, «el encargo procedente del servicio público de empleo para impartir un curso de formación» ${ }^{59} \mathrm{O}$, con carácter más general, «unas obras de construcción», en las cuales la Administración asume la posición de mero promotor, comenzando la cadena de contratistas y, por tanto, responsables, en la primera empresa constructora ${ }^{60}$.

\subsection{La inoperante regla de la subsidiariedad}

Si la contrata o subcontrata no viniera referida a la «propia actividad» del poder adjudicador, éste no resulta responsable ni solidaria ni subsidiariamente en materia retributiva. Es más, aunque la norma paccionada sectorial aplicable a la empresa contratista imponga responsabilidad subsidiaria de la corporación principal en cuanto a los impagos de salarios sin la concurrencia del requisito de «propia actividad», tal previsión no puede extender su eficacia a las entidades y organismos públicos que no sean del sector y por tanto no hayan intervenido en la negociación y firma del convenio (Roqueta, 2018: 108).

Llegados a este punto, procede abrir un paréntesis para señalar que el art. $42.1 \mathrm{ET}$ obliga «al empresario principal respecto del contratista (y al contratista respecto del subcontratista) a comprobar que éstos están al corriente en el pago de las cuotas a la Seguridad Social. A estos efectos, se debe recabar por escrito certificación de descubiertos a la Tesorería General de la Seguridad Social, que deberá librarla en el plazo de 30 días improrrogables». Transcurrido este lapso, quedará eximido de responsabilidad el empresario solicitante. Esa responsabilidad exonerable va referida a la solidaria que, en materia de Seguridad Social, contraiga la empresa contratista o subcontratista durante la ejecución de la contrata o subcontrata en virtud del propio art. 42 ET. Si no se solicita la certificación o se expide en sentido positivo, no hay tal exoneración. Ahora bien, la LCSP exige que el candidato a contratar con un Ente administrativo acredite documentalmente unos requisitos de capacidad y solvencia mucho más estrictos que los exigidos al particular que quiere convenir un vínculo contractual con otro sujeto privado. Entre ellos, el art. 71.1 d) LCSP «prohíbe contratar con la Administración a quien no se encuentre al corriente en el cumplimiento de las obligaciones en materia de Seguridad Social»

42 STSJ, Social, Canarias, de 12 de enero de 1998 (RJ 1998, 6216).

43 SSTSJ, Social, Murcia, de 20 de marzo de 2013 (rec. 1135/2012) y Madrid, de 17 de febrero de 2014 (rec. 1385/2013).

44 STSJ, Social, País Vasco, de 3 de mayo de 2005 (rec. 3137/2004).

45 STS, Social, de 27 de julio de 1998 (RJ 1998, 6216).

46 STSJ, Social, Canarias, de 30 de septiembre de 2015 (rec. 145/2015).

47 STSJ, Social, Cataluña, de 25 de enero de 2002 (AS 2002, 1079).

48 SSTS, Social, de 23 de enero, 24 de junio y 3 de octubre de 2008 (RJ 2008, 2775, 4233 y 359050 ).

49 STSJ, Social, Cantabria, de 8 de septiembre de 2004 (rec. 365/2004).

50 SSTS, Social, de 5 de diciembre de 2011 (rec. 4197/2010) y 30 de marzo de 2012 (rec. 4197/2010)

51 STS, Social, de 21 de febrero de 2018 (rec. 251/2016).

52 STSJ, Social, Asturias, de 31 de enero de 2017 (rec. 2855/2016).

53 STSJ, Social, Valencia, de 11 de diciembre de 2014 (rec. 1693/2014).

54 STSJ, Social, Madrid, de 12 de julio de 1997 (AS 1997, 2632).

55 STSJ, Social, Madrid, de 13 de junio de 2001 (rec. 824/2001).

56 STSJ, Social, Cataluña, de 23 de septiembre de 1998 (AS 1998, 6948).

57 SSTS, Social, de 18 de enero de 1995 (RJ 1995, 514) y 15 de julio de 1996 (RJ 1996, 5990).

58 STSJ, Social, Cataluña, de 1 de febrero y 1 de abril de 1997 (AS 1997, 712 y 1994).

59 STS, Social, de 29 de octubre de 1998 (AS 1998, 9049).

60 STS, Social, de 3 de julio de 2012 (rec. 2948/2011), citando, a su vez, las SSTS, Social, de 20 de julio de 2005 (rec. 2160/2004) y de 2 de octubre de 2006 (rec. 1212/2005). También SSTSJ, Social, Castilla y León, de 30 de marzo de 2011 (rec. 194/2011) y Valencia, de 30 de diciembre de 2011 (rec. 1723/2011). 
(Bermejo, 2008: 109), extremo que deberá justificar aportando la documentación pertinente, de manera que la exoneración de responsabilidad a la que alude el art. 42.1 ET concurrirá en todo caso.

\subsection{Situaciones de desprotección}

La limitación de responsabilidades del empresario principal, es decir, de la Administración, a las contratas y subcontratas de propia actividad a la luz del art. $42 \mathrm{ET}$, expulsa del ámbito de protección a los trabajadores de adjudicaciones relacionadas con actividades auxiliares, precisamente los más vulnerables dada la gran flexibilidad tanto de entrada, pues están sometidos a una utilización exorbitada de un contrato por obra o servicio supeditado a la duración del encargo, como de salida ante la facilidad de instrumentar los despidos por causas objetivas, unidas a una falta de cobertura convencional clara (Esteve, 2018: 113). Nada soluciona la regla de cierre establecida en los arts. 142.1 y 168.1 TRLGSS, que regulan, para los supuestos en los que no existiera responsabilidad solidaria por no tratarse de propia actividad o por haberse aplicado el mecanismo de exoneración del art. 42.1 ET, una responsabilidad subsidiaria del empresario principal, tanto en relación con cotizaciones como con prestaciones por falta de afiliación o alta, pues, en la práctica, no va a ser asumida por la Administración como empresario principal atendiendo a las reglas sobre las prohibiciones de contratar establecidas en la LCSP anteriormente mencionadas ${ }^{61}$.

La dimensión garantista desde la perspectiva laboral es, por ende, muy débil y la tutela de la normativa administrativa es inexistente. Conviene recordar que el art. 130.6 LCSP trata de evitar la traslación de la deuda al nuevo contratista pero su marco de aplicación se reduce a los supuestos de subrogación por sucesión de la actividad de aquél, no a los de subcontratación, tal y como se deduce de un tenor literal que sienta cómo: «sin perjuicio de la aplicación, en su caso, de lo establecido en el art. $44 \mathrm{ET}$, el pliego de cláusulas administrativas particulares siempre contemplará la obligación del contratista saliente de responder de los salarios impagados a los trabajadores afectados por subrogación, así como de las cotizaciones a la Seguridad Social devengadas, aún en el supuesto de que se resuelva el contrato y aquellos sean subrogados por el nuevo contratista, sin que en ningún caso dicha obligación corresponda a este último. En este caso, la Administración, una vez acreditada la falta de pago de los citados salarios, procederá a la retención de las cantidades debidas al contratista para garantizar el pago de los citados salarios, y a la no devolución de la garantía definitiva en tanto no se acredite el abono de éstos» (Fernández, 2018: 113). Tal regulación tuitiva, sin duda, queda extramuros del supuesto aquí analizado.

Cabe dar noticia, como reflexión abierta a la crítica, que, en frecuentes ocasiones, dentro de los pliegos de condiciones ( «ley primordial del contrato» o «lex inter partes»), se incorporan, «a favor de la Administración comitente, cláusulas exoneratorias de la responsabilidad que pudiera derivarse del incumplimiento por el adjudicatario o los sucesivos subcontratistas de la normativa laboral y de protección social. La autoexoneración de responsabilidad prevista en los mismos hace depender, no obstante, la aplicabilidad de una norma imperativa, como es el art. $42 \mathrm{ET}$, de la voluntad unilateral de la parte obligada a cumplirla, lo cual no puede ser admitido en ningún caso, pues dicho precepto estatutario establece un régimen de responsabilidad empresarial solidaria a favor de los trabajadores indisponible para las partes e inderogable para la Administración» (Rodríguez, 2010: 53). Una restricción explícita a la inclusión de este tipo de previsiones exoneratorias en los pliegos impediría, empero, el surgimiento de muchas dificultades planteadas en la práctica, que han llevado a la judicialización de los problemas con el inherente rechazo para la satisfacción de los intereses de los trabajadores.

Por tanto y ante tales puntos endebles, es necesario el diseño de un sistema de responsabilidad conjunta de la Administración y de los sucesivos contratistas verdaderamente disuasorio de prácticas ilícitas, incrementadas exponencialmente por las empresas multiservicios.

\section{CONCLUSIÓN}

La reducción de costes a la hora de colaborar en la dispensa de servicios públicos que las empresas multiservicios ofrecen a las Administraciones Públicas, ha conllevado una preocupante minoración de salarios y de otros estándares laborales. Aun cuando el paso dado desde la legislación de contratos del sector público en aras a la mejora de las condiciones laborales de los asalariados al servicio de las empresas con-

61 SSTS, Social, de 23 de septiembre de 2008 (rec. 1048/2007) y 9 de diciembre de 2010 (rec. 1266/2010). 
tratistas y concesionarias ha sido de gigante, es necesario seguir avanzando en esta senda desde la legislación laboral diseñando varias actuaciones sucesivas al objeto de cubrir las lagunas aun existentes, sobre todo en los supuestos de subcontratación, donde las responsabilidades empresariales quedan ampliamente diluidas. En primer lugar, garantizando la imputabilidad solidaria por deudas salariales y con la Seguridad Social más allá del concepto de propia actividad. En segundo término, reformulando las causas del contrato a término por obra o servicio determinado para vetar su utilización asociada a las contratas, de manera que quede ceñido su ámbito objetivo a los supuestos de contratación directa. En tercer lugar, replanteando el régimen de solidaridad y subsidiariedad en la responsabilidad empresarial, que no debería restringirse a las deudas salariales y de Seguridad Social, sino a las laborales en general y a otras deudas como el recargo de prestaciones. En cuarto término, equiparando las condiciones sociales y económicas de los asalariados de las contratas con los de la empresa principal (Administración, in casu), aplicando analógicamente las previsiones de las empresas de trabajo temporal, que, en el momento presente, únicamente están vetadas en el sector público para asumir «servicios que impliquen ejercicio de la autoridad inherente a los poderes públicos» (art. 17 LCSP). Y, en quinto lugar, estableciendo una regulación laboral ad hoc para tales las empresas adjudicatarias iniciales o sucesivas de servicios públicos.

\section{REFERENCIAS BIBLIOGRÁFICAS}

BASSOLS COMA, M. (2007): “La externalización: tendencias en el Derecho Administrativo español”, en Le Esternalizzazioni, Atti del XVI Convegno degli amministrativisti italo-spagnoli. Genova: Bologna.

BAYLOS GRAU, A. (1988): Derecho de huelga y servicios esenciales. Madrid: Tecnos.

BERMEJO VERA, J. (2008): "Las prohibiciones de contratar en la Ley de Contratos del Sector Público", en Revista Aragonesa de Administración Pública, núm. monográfico.

CANTERO MARTÍNEZ, J. (2011): "La decisión administrativa de externalizar y su repercusión en el empleo público. Límites y pautas para su adopción”, en ORTEGA ÁLVAREZ, L. (dir.): Crisis y externalización en el sector público: ¿solución o problema? Madrid: INAP.

CAVAS MARTÍNEZ, F. (2018): "Las cláusulas sociales sobre fomento, calidad y mantenimiento del empleo en la contratación pública”, en GARCÍA ROMERO, B. y PARDO LÓPEZ, M. M. (dirs.): Innovación social en la contratación administrativa: las cláusulas sociales. Pamplona: Aranzadi.

CORDERO GONZÁLEZ Y VIVERO SERRANO, J. B. (2018): "El mantenimiento de los servicios esenciales de la comunidad: un balance", en SANGUINETTI RAYMOND, W. y CABERO MORÁN, E. (dirs.): Sindicalismo y democracia. El Derecho Sindical Español del profesor Manuel Carlos Palomeque treinta años después (19862016). Granada: Comares.

CRUZ VILLALÓN, J. (1992): "Descentralización productiva y responsabilidad laboral por contratas y subcontratas", en Relaciones Laborales, núm. 2.

ESTEVE SEGARRA, M. A. (2016): "Cesión ilegal en las Administraciones Públicas a través de las empresas de servicios", en Revista Trabajo y Seguridad Social (Centro de Estudios Financieros), núm. 399.

ESTEVE SEGARRA, A. (2018): "Empresas multiservicios: cesión ilegal de trabajadores y subcontratación", en MONEREO PÉREZ, J. L. y PERÁN QUESADA, S. (dirs.): La externalización productiva a través de la subcontratación empresarial. Granada: Comares.

FERNÁNDEZ LÓPEZ, M. F. (2018): “Las responsabilidades empresariales en el ámbito del trabajo en contratas", en Descentralización productiva: nuevas formas de trabajo y organización empresarial. XXVIII Congreso de Derecho del Trabajo y de la Seguridad Social. Madrid: Cinca.

FERRANDO GARCÍA, F. y RODRÍGUEZ EGÍO, M. (2017): "Las cláusulas sociales en la contratación pública a la luz de la doctrina del TJUE: un ejemplo de la controversia entre las libertades económicas y la protección frente al dumping social", en GARCÍA ROMERO, B. y PARDO LÓPEZ, M. M. (dirs.): Innovación social en la contratación administrativa: las cláusulas sociales. Pamplona: Aranzadi.

GALA DURÁN, C. (2010): "Responsabilidad social empresarial, derecho a la libre prestación de servicios y contratación pública de obras o servicios", en Relaciones Laborales, núm. 13.

GARATE CASTRO, J. (2018): “Descentralización productiva y Derecho del Trabajo”, en AA.VV: Descentralización productiva: nuevas formas de trabajo y organización empresarial. XXVIII Congreso de Derecho del Trabajo y de la Seguridad Social. Madrid: Cinca.

GIMENO FELIU, J. M. (2014): El nuevo paquete legislativo comunitario sobre contratación pública. De la burocracia a la estrategia. El contrato público como herramienta del liderazgo institucional de los poderes públicos. Pamplona: Aranzadi.

GOERLICH PESET, J. M. (2018): "Ejercicio del derecho de huelga en el contexto de la descentralización productiva", en Descentralización productiva y nuevas formas de trabajo y organización empresarial. XXVIII Congreso de Derecho del Trabajo y de la Seguridad Social. Madrid: Cinca. 
GONZÁLEZ ORTEGA, S. (2018): "El derecho de huelga: un derecho fundamental acorralado", en Revista Trabajo y Seguridad Social (Centro de Estudios Financieros), núm. 418.

GRAU PINEDA, C. (2018): "Las estructuras empresariales complejas y el conflicto colectivo. Viejas y nuevas manifestaciones de esquirolaje”, en Poder de dirección y estructuras empresariales complejas. Madrid: Cinca.

IZQUIERDO HERNÁNDEZ, F. J. y MOLINA GARCÍA, M. (1996): La laboralización de los funcionarios públicos. Valencia: Tirant Lo Blanch.

LARRAZABAL ASTIGARRAGA, E. (2015): "La introducción del salario mínimo en la contratación pública: análisis jurisprudencial del TJUE y del TSJPV", en Revista de Derecho Social, núm. 71.

LARRAZABAL ASTIGARRAGA, E. (2016): "La influencia de la nueva regulación sobre contratación pública en materia de cláusulas sociales", en Revista General de Derecho del Trabajo y de la Seguridad Social, núm. 42.

LARRAZABAL ASTIGARRAGA, E. (2017): "La jurisprudencia del Tribunal Supremo sobre la posibilidad de exigir la aplicación del convenio colectivo del lugar de ejecución en la contratación pública”, en Lan Harremanak, núm. 36, Tomo I. DOI: https://doi.org/10.1387/lan-harremanak.17930.

MANTECA VELARDE, V. (2005): "El derecho a ser contratista", en Contratación Administrativa Práctica, núm. 40.

MARCOS GONZÁLEZ, J. I. (2015): "Cláusulas sociales en los contratos del sector público: ¿una opción legal de corrección de la reforma laboral? Comentario a la Sentencia del Tribunal Superior de Justicia del País Vasco, Sala de lo Contencioso-Administrativo, de 30 de diciembre de 2014, rec. núm. 643/2013", en Revista Trabajo y Seguridad Social (Centro de Estudios Financieros), núm. 387.

MARTÍN HERNÁNDEZ, M. L. (2018): "Principales aspectos sociolaborales de la Ley 9/2017, de 8 de noviembre, de Contratos del Sector Público", en Trabajo y Derecho, núm. 37.

MERCADER UGUINA, J. R. (2018): "Marco jurídico de los trabajadores en la empresa principal y empresas subcontratistas", en MONEREO PÉREZ, J. L. y PERÁN QUESADA, S. (dirs.): La externalización productiva a través de la subcontratación empresarial. Granada: Comares.

MERINO SEGOVIA, A. (2018): "La problemática legitimación de las representaciones sociales para negociar y suscribir convenios colectivos en las empresas multiservicios", en CRUZ VILLALÓN, J. (dir.): La negociación colectiva como instrumento de gestión del cambio. Madrid: Cinca.

MIRANDA BOTO, J. M. (2016): "Contratación pública y cláusulas de empleo y condiciones de trabajo en el Derecho de la Unión Europea”, en Lex Social: Revista de los derechos sociales, núm. 2.

MOLINA NAVARRETE, C. (2016): "Cláusulas sociales, contratación pública: del problema de legitimidad al de sus límites", en Temas Laborales, núm. 135.

MOLINA NAVARRETE, C. (2017): El nuevo Estatuto de los Trabajadores a la luz de la jurisprudencia comunitaria. Madrid: La Ley.

MONEREO PÉREZ, J. L. (2007): "Precariedad laboral y formas de gestión indirectas de mano de obra: ETT y subcontratación”, Jornadas CARL.

MONEREO PÉREZ, J. L. (2015): "Aspectos laborales de la interconexión entre Administraciones Públicas y entes instrumentales: irregularidades en la contratación y legislación de emergencia”, en Revista de Derecho Social, núm. 67.

MONEREO PÉREZ, J. L. (2018): "Identidad de las empresas de servicios. Régimen jurídico y responsabilidades", en Descentralización productiva: nuevas formas de trabajo y organización empresarial. XXVIII Congreso de Derecho del Trabajo y de la Seguridad Social. Madrid: Cinca.

MORENO MORCILLO, J. (2016): "Las cláusulas sociales en la contratación pública como garantía frente al dumping social intracomunitario", en Revista Aragonesa de Administración Pública, núm. 5.

MORENO VIDA, M. N. (2015): "La intervención administrativa en las huelgas en servicios esenciales de la comunidad", en Temas Laborales, núm. 125.

NORES TORRES, L. E. (2004): El trabajo en contratas. La noción de «contrata de propia actividad». Valencia: Tirant Lo Blanch.

PAREJO ALFONSO, L. (1989): "La eficacia como principio jurídico de la actuación de la Administración Pública”, en Documentación Administrativa, núm. 218-219. DOI: https://doi.org/10.24965/da.v0i218-219.5132.

PÉREZ DEL RÍO, T. y ZAMBONINO PULITO, M. (2008): "La acción positiva y sus instrumentos: la inclusión de las cláusulas sociales de género en la contratación de las Administraciones Públicas", en Revista de Derecho Social, núm. 43.

PÉREZ-ILLARBE, J. A. (2006): "Las cláusulas sociales en la reforma de la legislación de contratos del sector público", en Zerbitzuan, núm. 40.

PINTOS SANTIAGO, J. (2017): Los principios generales de desarrollo humano y sostenibilidad ambiental en la contratación pública. Madrid: INAP.

RODRÍGUEZ ESCANCIANO, S. (2006): Subcontratación de concesiones administrativas: problemas laborales. Madrid: Marcial Pons.

RODRÍGUEZ ESCANCIANO, S. (2010): El fenómeno de la sucesión empresarial en la Administración Pública: requisitos y consecuencias de la aplicación de los arts. 42, 43 y 44 del Estatuto de los Trabajadores. Barcelona: Federación de Municipios de Cataluña.

RODRÍGUEZ-PIÑERO ROYO, M. (2014): “Aproximación a la colaboración público-privada en el mercado de trabajo español”, en Temas Laborales, núm. 25. 
RODRÍGUEZ-PIÑERO Y BRAVO-FERRER, M. (2005): "La contratación administrativa y el Derecho del Trabajo”, en Relaciones Laborales, núm. 11.

ROJAS RIVERO, G. P. (2018): "Negociación colectiva y convenio colectivo aplicable en empresas multiservicios", en Descentralización productiva: nuevas formas de trabajo y organización empresarial. XXVIII Congreso de Derecho del Trabajo y de la Seguridad Social. Madrid: Cinca.

ROMERO RUÍZ, A. (2017): "Las cláusulas sociales en el proyecto de Ley de Contratos del Sector Público y el nuevo paradigma de la contratación pública", en Revista Vasca de Administración Pública, núm. 108.

ROQUETA BUJ, R. (2018): El empresario público. La gestión del personal laboral tras la nueva Ley de Contratos del Sector Público. Pamplona: Aranzadi.

SANGUINETTI RAYMOND, W. (2007): "Privatización de la gestión de servicios públicos y precarización del empleo: la inaplazable necesidad de un cambio de modelo", en Revista de Derecho Social, núm. 39.

TASCÓN LÓPEZ, R. (2018): El esquirolaje tecnológico. Pamplona: Aranzadi.

TOSCANI GIMÉNEZ, D. y VALENCIANO SAL, A. (2016): "Cambio de criterio del TJUE ante la posibilidad de fijar un salario mínimo a respetar en la ejecución de contratos en el ámbito de la contratación pública: comentario a la Sentencia del Tribunal de Justicia de la Unión Europea. Asunto C-115/14 (RegioPost GmbH amp; Go KG/Stadt Landau in der Pfalz) de 17 de noviembre de 2015", en Unión Europea Aranzadi, núm. 1.

TRILLO PARRAGA, F. J. (2017): Externalización de servicios públicos y su impacto en los derechos laborales. Albacete: Bomarzo.

VALLECILLO GÁMEZ, M. R. (2017): “Aspectos sociolaborales de la nueva Ley de Contratos del Sector Público", en Revista Trabajo y Seguridad Social (Centro de Estudios Financieros), núm. 417.

VÁZQUEZ LACUNZA, E. (2016): "El pago de un salario mínimo como condición especial de ejecución en los contratos públicos", en Contratación Administrativa Práctica, núm. 146.

VICENTE PALACIO, A. (2018): "Empresas de servicios: negociación colectiva y subcontratación", en MONEREO PÉREZ, J. L. y PERÁN QUESADA, S. [dirs.]: La externalización productiva a través de la subcontratación empresarial. Granada: Comares.

VILLAR ROJAS, F. (2007): "La concesión como modalidad de colaboración privada en los servicios sanitarios y sociales", en Revista de Administración Pública, núm. 172. 